\title{
EXPERIMENTAL ANALYSIS OF TOUGHNESS IN 6156 AL-ALLOY SHEET FOR AEROSPACE APPLICATIONS
}

\author{
T.F. Morgeneyer ${ }^{a}$, M.J. Starink ${ }^{b}$ and I.Sinclair ${ }^{c}$ \\ Materials Research Group, School of Engineering Sciences, University of Southampton, \\ Southampton, SO17 1BJ, United Kingdom \\ atm504@soton.ac.uk, bm.j.starink@soton.ac.uk, ${ }^{\mathrm{c}}$ i.sinclair@soton.ac.uk
}

Keywords: AA6156, Al-Mg-Si-Cu Alloys, Toughness, Quench Sensitivity, Precipitate Free Zone

\begin{abstract}
Analysis of toughness in $6156 \mathrm{Al}-\mathrm{Mg}$-Si-Cu sheet has been performed using enhanced Kahn tear tests on samples quenched at different rates, whilst microstructures of the samples have been assessed using differential scanning calorimetry, scanning electron microscopy and transmission electron microscopy. Crack initiation energies were unaffected by changing water quench temperature from $20^{\circ} \mathrm{C}$ to $60^{\circ} \mathrm{C}$, however a significant reduction was evident on air cooling. Crack propagation resistance was reduced for both $60^{\circ} \mathrm{C}$ water quenched and air cooled materials. The failure morphology of the air cooled material appears consistent with classical intergranular ductile failure. Coarse voiding and shear decohesion was prevalent in the $20^{\circ} \mathrm{C}$ water quenched material, whilst the $60^{\circ} \mathrm{C}$ water quenched material showed a mixture of transgranular and intergranular fracture modes. Changes in microstructure and precipitation behaviour resulting from reduced quenching rate were identified and related to the observed fracture behaviour, particularly in terms of precipitate free zone formation and the simultaneous presence of coarse particles at grain boundaries.
\end{abstract}

\section{Introduction}

There has been interest in substituting welds for the riveted joints commonly employed in fuselage structures to save cost and reduce mass of airframes [1]. As such, alloys offering improved weldability over established AA2024-type damage tolerant materials are of significant potential value. 6X56 Al-Si-Mg-Cu alloys display good weldability, low density, good corrosion resistance and equivalent mechanical properties to AA2024, and are hence considered as a potential replacement. These alloys contain relatively high solute levels which can cause quench sensitivity [2]. In the damage tolerant applications envisaged, potential quench sensitivity in toughness is therefore of interest [3]. The main aim of the present study is to quantify and micromechanically characterise toughness changes as a function of reduced quench rates in 6 X56 alloys.

\section{Experimental}

AA6156 sheet was supplied by Alcan CRV. The nominal composition is given in table 1 .

\begin{tabular}{|l|l|l|l|l|l|l|}
\hline $\mathrm{Si}$ & $\mathrm{Fe}$ & $\mathrm{Cu}$ & $\mathrm{Mn}$ & $\mathrm{Mg}$ & $\mathrm{Cr}$ & $\mathrm{Zn}$ \\
\hline $0.7-1.3$ & $<0.2$ & $0.7-1.1$ & $0.4-0.7$ & $0.6-1.2$ & $<0.25$ & $0.1-0.7$ \\
\hline
\end{tabular}

Table 1 composition of the AA6156 alloy

Samples of $3.2 \mathrm{~mm}$ thickness were solutionized at $550^{\circ} \mathrm{C}$ for $30 \mathrm{~min}$ and subsequently quenched by quenching in water at $20^{\circ} \mathrm{C}$, in water at $60^{\circ} \mathrm{C}$ and by cooling in still air. All three types of sample were subsequently subjected to a heat ramp of $20^{\circ} \mathrm{C} / \mathrm{h}$ up to $190^{\circ} \mathrm{C}$ where they were held for $4 \mathrm{~h}$ (reaching peak age, T6). Kahn tear tests are performed to measure fracture toughness. The Kahn specimens were fractured under displacement control in general accord with [4]. 
Scanning Electron Microscope (SEM, Jeol 6500F) images were obtained from a range of locations on the fractured Kahn test specimens. Transmission Electron Microscopy (TEM, Jeol $3010)$ has been carried out at $300 \mathrm{kV}$. The samples were prepared by cutting thin slices $(\sim 0.3 \mathrm{~mm})$ from the quenched and aged samples, punching a $3 \mathrm{~mm}$ diameter disc and grinding it to a thickness of about $0.2 \mathrm{~mm}$. Subsequent electropolishing was performed with a twin jet electropolisher using a solution of $30 \% \mathrm{HNO}_{3}$ and $70 \%$ methanol maintained at -20 and $-30^{\circ} \mathrm{C}$.

Differential Scanning Calorimerty (DSC) was conducted at a heating rate of $10^{\circ} \mathrm{C} /$ minute using a Perkin Elmer Pyris on samples quenched as above and subsequently aged for three days at room temperature. DSC curves are shown after correction for baseline and heat capacity effects [5], i.e. they represent the heat flow due to reactions in the sample.

\section{Results}

TEM: Despite the fast quench, $20^{\circ} \mathrm{C}$ water-quenched samples exhibited precipitate free zones (PFZs) at the grain boundaries, along with some particle decoration of the boundaries, see Fig. 1(a).
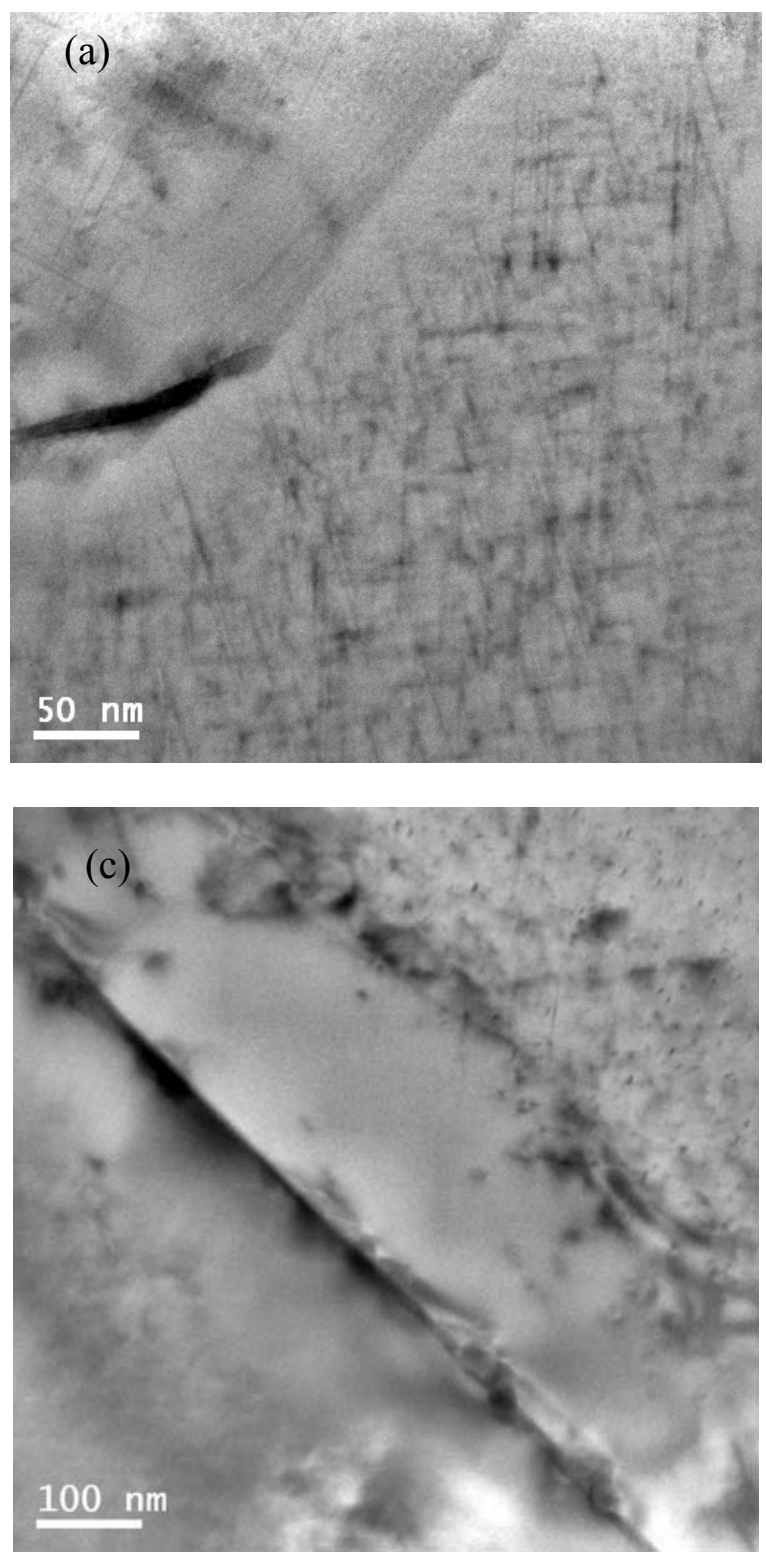

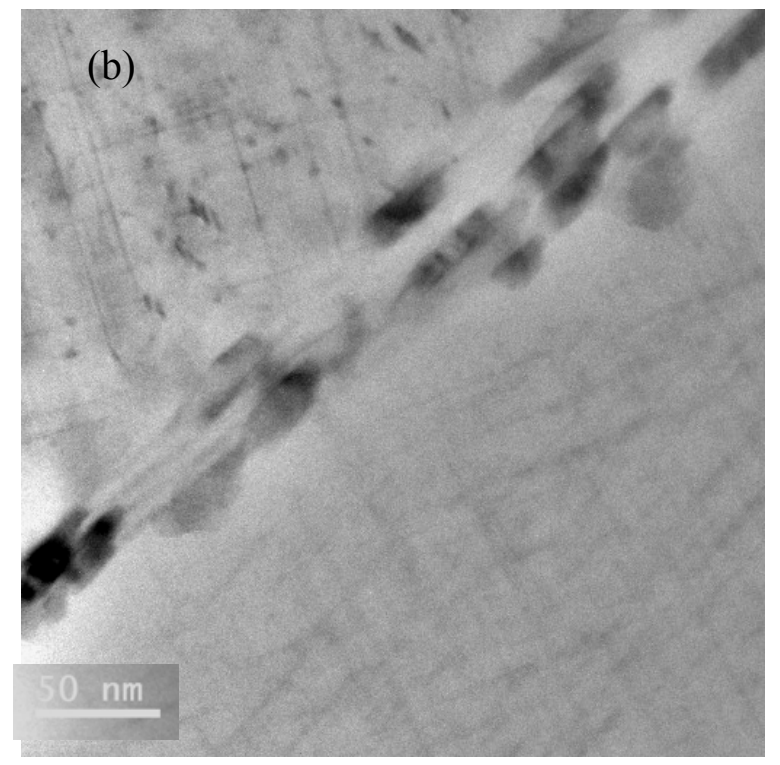

Fig. 1 TEM micrographs of intergranular precipitates after (a) $20^{\circ} \mathrm{C}$ water quench and ageing, (b) $60^{\circ} \mathrm{C}$ water quench and ageing (c) air cool and ageing 
On the investigated grain boundaries, PFZ total width varied between 40 and $70 \mathrm{~nm}$. For the slower quench rate of $60^{\circ} \mathrm{C}$ water quench, the loss of solute to quench-induced precipitation becomes visible (see Fig. 1(b)). There is a slight increase in PFZ width (80-100nm) and a substantial increase in grain boundary particle coverage. In the air cooled material, the quench induced precipitates cover the majority of the observed grain boundary area. A PFZ width of $\sim 400 \mathrm{~nm}$ was discernable (see Fig.1(c)). In the first instance, no significant quench-induced heterogeneous precipitation was identified on dispersoid particles for the water quenched materials, however large elongated particles ( $\sim 500 \mathrm{~nm}$ in length) were clearly seen on the dispersoids of the air cooled material, surrounded by a substantial PFZ.

The width of hardening precipitates was of the order of several nanometers (Fig. 5(a)). The selected area diffraction (SAD) patterns in [100] directions (not presented here) are essentially similar for the two types of water quenched samples, with streaks, and local maxima on the streaks that are consistent with patterns obtained for alloys with similar compositions $(\mathrm{Cu}$ containing 6xxx alloys with excess $\mathrm{Si}$ ) [6,7,8]. In Ref. [8] it is suggested that the precipitates formed in such materials are $\beta^{\prime \prime}$ and a lath shaped precipitate, whilst Ref [7] suggests that $\lambda^{\prime}$ will be present in this alloy. Additional diffraction spots were seen in the present air cooled material but have not been identified as yet.

DSC: Fig. 2 shows DSC results for the three investigated treatments. The endothermic effect I appearing in the water quenched materials is consistent with GP zone dissolution [9] and the strong exothermic effect II is attributable the precipitation of $\beta^{\prime \prime}$ and/or $\lambda^{\prime}$ (see Ref.[6,7]). The smaller exothermic effect III is possibly due to the precipitation of the $\beta^{\prime}$. The subsequent large endothermic effect IV is due to the dissolution of stable precipitate phases.

The peaks for the GP zone dissolution (effect I) as well as for the $\beta^{\prime \prime}$ or $\lambda^{\prime}$ precipitate formation (effect II) are more pronounced for the $20^{\circ} \mathrm{C}$ water quenched material as compared to the $60^{\circ} \mathrm{C}$ water quenched material. In the thermogram of the air cooled material the peaks are significantly less intense than for the water quenched materials. The GP zone dissolution peak is weak whilst the two exothermic peaks between 220 and $300^{\circ} \mathrm{C}$ observed for the water quenched materials appear to have merged into one broad, less intense peak. These phenomena are consistent with heterogeneous precipitation during the slower quenches and the attendant "loss" of solute, in keeping with the TEM observation of grain boundary precipitation.

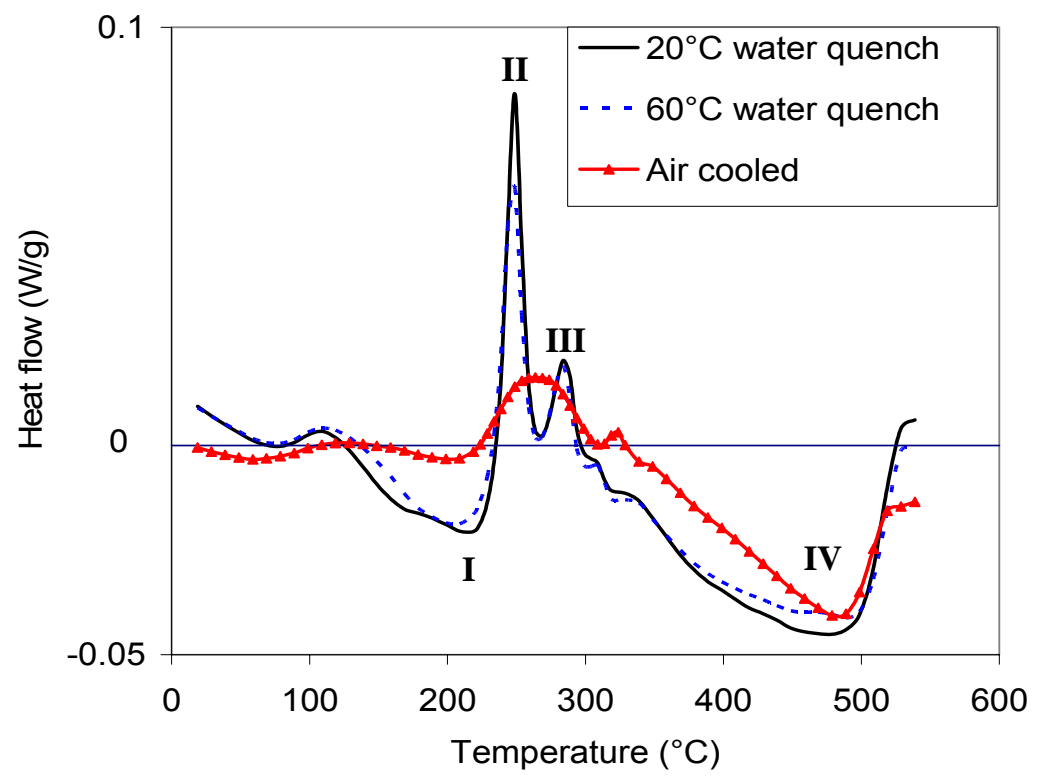

Fig. 2 DSC thermograms, taken at a scan rate of $10^{\circ} \mathrm{C}$ per min for the samples quenched at different rates and subsequently aged at room temperature for 3 days 
Kahn Tear Testing: In the Kahn tear tests the crack length and the force F divided by the initial ligament area $\mathrm{A}_{0}$ are measured as a function of crack tip opening displacement (COD), $l_{C O D}$. Typical data are shown in Fig. 3, showing both crack length and $F / A_{0}$ in one graph.

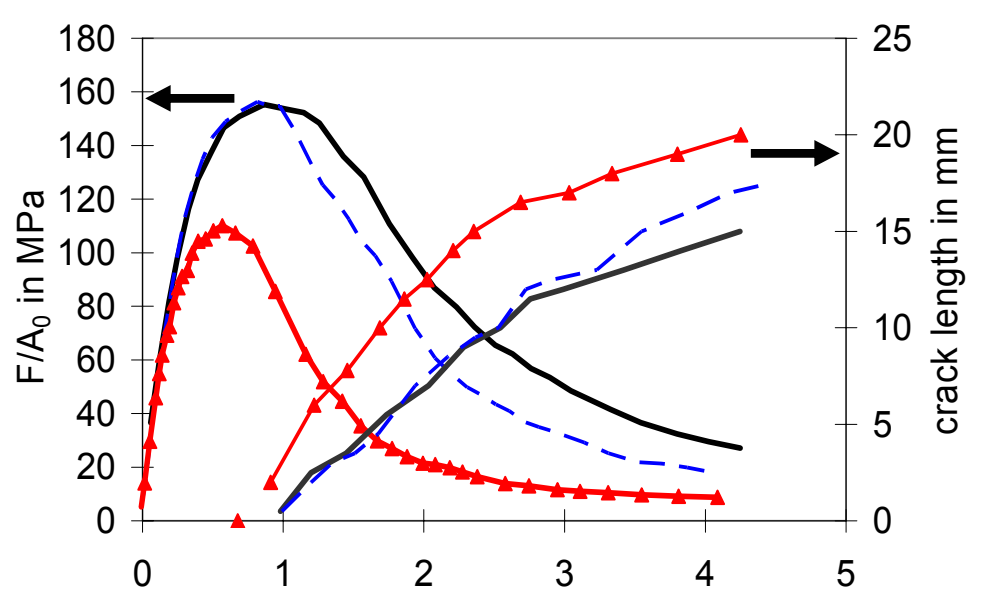

Crack Tip Opening Displacement (COD) in mm $-20^{\circ} \mathrm{C}$ water quenched and peak aged

$--60^{\circ} \mathrm{C}$ water quenched and peak aged

- Air cooled and peak aged

Fig. 3 Kahn tear test results: nominal stress $\left(\mathrm{F} / \mathrm{A}_{0}\right)$ versus crack tip opening displacement and crack length versus crack tip opening displacement for different quench rates.

The initial nominal stresses of the $20^{\circ} \mathrm{C}$ water quenched and the $60^{\circ} \mathrm{C}$ water quenched materials are very similar. After achieving the maximum nominal stress however, the stresses are appreciably lower for the $60^{\circ} \mathrm{C}$ water quenched material as compared to the $20^{\circ} \mathrm{C}$ water quench at the same COD. The propagation fracture toughness (defined as the integral $\int F / A_{0} \mathrm{~d} l_{C O D}$ between a crack length of $5 \mathrm{~mm}$ and $15 \mathrm{~mm}$ ), is clearly lower for the $60^{\circ} \mathrm{C}$ water quenched material than for the $20^{\circ} \mathrm{C}$ quenched material. The air cooled material fails at consistently lower loads than the water quenched materials; the initial nominal stresses as well as the nominal stresses during crack propagation are markedly reduced. The crack also grows faster (as a function of COD) in the air cooled material than in the water cooled materials, indicative of much reduced toughness.

Fractography: On a macroscopic scale, the fractured tear test samples show a broadly triangular region where the crack surface is normal to the main tensile axis, followed by a transition to a slant $\left(\sim 45^{\circ}\right)$ fracture mode, consistent with the evolution of the triaxial constraint conditions [10]. Fig. 4 shows SEM images of typical fracture surfaces of the three samples at the triangular region of crack growth, as indicated in Fig. 4(d). Fig. 4(a) shows a detailed image of a typical fracture surface region of the $20^{\circ} \mathrm{C}$ water quenched material. Coarse voiding is the prevailing feature of this condition (void diameters of the order of $10-40 \mu \mathrm{m}$ ). The voids are evidently associated with coarse second phase particles, with a relatively small amount of final coalescence via finer, secondary void formation. Similar to the $20^{\circ} \mathrm{C}$ water quenched material, coarse voiding is generally prevalent in the $60^{\circ} \mathrm{C}$ water quenched material, Fig. 4(b). However, there are also regions of elongated, relatively planar features, exhibiting very fine-scale, shallow voids (void diameters of the order of $1 \mu \mathrm{m}$ ). With ongoing crack growth into the slant fracture regions of both water quenched conditions, an increasing propensity for ductile shear decohesion was noted, with a marked reduction in the proportion of coarse voiding. In Fig. 4(c), typical of the air cooled materials, the elongated planar features are more pronounced, covering the majority of the fracture surfaces. Evidence of ductile failure is seen at larger intermetallic particles on the fracture surface: however void growth is apparently constrained by the onset of the fine-scale voiding process. The failure morphology of the air cooled material is consistent with classical intergranular ductile failure and is dominant in both macroscopically flat and sheared regions of the fracture surfaces [11].

Further charaterisation of the evolution of damage mechanisms has also been carried out via 3D micro-tomography (not presented here) on water quenched samples $60^{\circ} \mathrm{C}$, revealing classical 
ductile fracture features such as coarse equiaxed voids, cracked large particles, coarse void clusters and coarse void coalescence by combinations of impingement and secondary cracking.
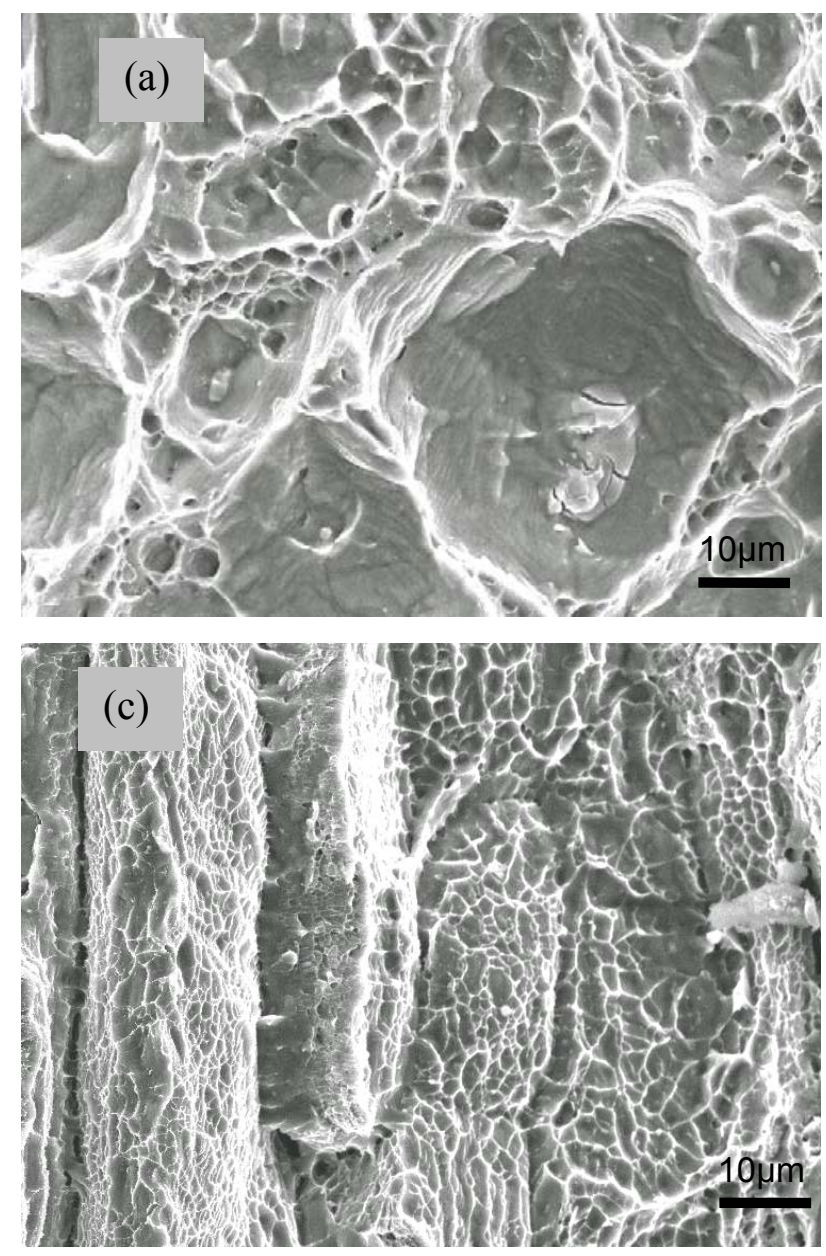

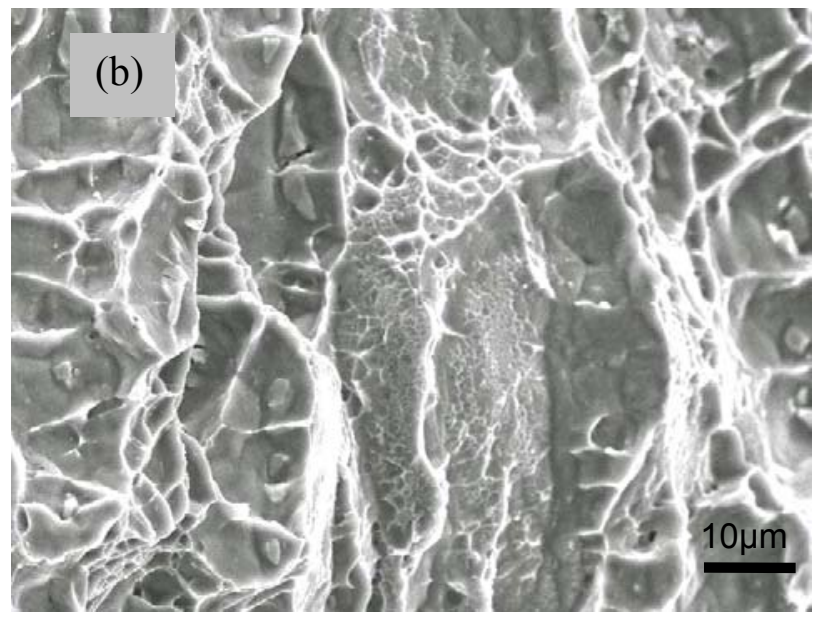

(d)

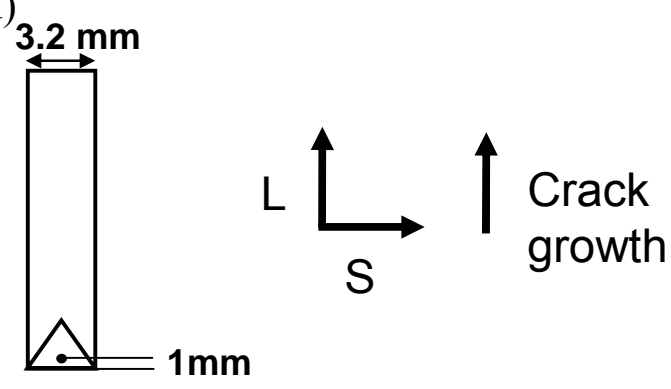

Fig. 4 SEM micrographs of the fracture surface of (a) the $20^{\circ} \mathrm{C}$ water quenched and peak aged material, (b) the $60^{\circ} \mathrm{C}$ water quenched and peak aged material, (c) the air cooled and peak aged material (d) Schematic illustration of macroscopic fracture surface regions and position of the images

\section{Discussion}

DSC data indicates that previously dissolved alloying elements precipitate partially during the slower cooling steps considered here. The associated precipitates may be expected to be relatively coarse and form preferentially at high energy interfaces, such as grain boundaries or second phase particles (such as dispersoids), with corresponding precipitate free zones (PFZs) being formed in the material around those sites where solute is effectively lost in the cooling procedure, as seen in the TEM. Such a combination of boundary particle decoration and PFZ formation has been widely discussed in relation to generation of boundary ductile failure (e.g. see [11]), consistent with the present reductions in toughness with reduced quench rates. Separating the potential influences of plastic strain partitioning within relatively soft PFZ material and local low strains to failure associated with a high density of void nucleating particles along the grain boundaries is extremely difficult to achieve. In terms of the present results it is interesting to note that plane strain dominated crack growth is evidently less susceptible to quench embrittlement, i.e. crack initiation toughness is not reduced by the $60^{\circ} \mathrm{C}$ quench (hardness testing showed no significant change in flow strength between the two water quenched materials, with the implication of essentially 
equivalent stress state evolution under load for these materials). Increased triaxiality is of course expected to favour coarse void growth over alternative damage mechanisms. During plane stress crack growth in the water quench materials, it is competition between shear decohesion and ductile boundary failure that may then be the key micromechanistic contribution to toughness changes, where it is interesting to note that through-thickness shear may more readily contribute to PFZ shear strain accumulation (and hence boundary failure).

\section{Conclusions}

Kahn tear tests and microstructural analysis was performed on 6156 samples which were quenched at different rates and subsequently artificially aged. This revealed:

- Both the coverage of grain boundary decoration and PFZ width increase with changing water quench temperature from $20^{\circ} \mathrm{C}$ to $60^{\circ} \mathrm{C}$. Heterogeneous precipitation and $\mathrm{PFZ}$ formation on dispersoids further occurred in the air cooled material.

- The DSC tests indicated a loss of solute during the slower quenches.

- The crack propagation energy is particularly reduced as a result of the reduction in quench rate, indicating an increased sensitivity of plane stress failure to changes in grain boundary character. Changes in toughness may then be particularly dominated by competition between shear decohesion and boundary ductile failure modes.

\section{Acknowledgements}

The authors would like to acknowledge Alcan CRV for financial support and material supply, and Frederic Bron and Bernard Bes for technical discussion. We would also like to thank Shuncai Wang for his help with electron microscopy.

\section{References}

[1] R. Dif, B. Bès, J.C. Ehrström, C. Sigli, T.J. Warner, Ph. Lassince and H. Ribes: Mater. Sci. Forum Vol. 331-337 (2000), p. 1613-1618

[2] P.A. Rometsch, M.J. Starink and P.J. Gregson: Mater. Sci. Eng. A Vol. 339 (2003) p. 255-264

[3] B. Morere, J.C. Ehrström, P.J. Gregson and I. Sinclair: Metall. Trans. A 31 (2000), p. 2503.

[4] ASTM-international, Standard Designation B 871 - 01. 2001: West Conshohocken, USA

[5] M.J. Starink: Int. Mater. Rev., Vol. 49 (2004), p. 191-226

[6] M. Tanaka and T. Warner : Mater. Sci. Forum Vol. 331-337 (2000), p. 983-988

[7] L. Sagalowicz, G. Hug, D. Béchet, P. Sainfort and G. Lepasset: Proc. $4^{\text {th }}$ Int. Conf. on Aluminium alloys, Atlanta, Georgia, USA, 636-643 (1994)

[8] D.J. Chakrabarti, and D.E. Laughlin: Prog. Mater. Sci. Vol. 49 (2002), p. 389-410

[9] A. Gaber, K. Matsuda, A.M. Ali, Y. Zou, S.Ikeno: Mater. Sci. Technol., Vol. 20 (2004), p. $1627-1631$

[10]J.F. Knott: Fundamentals of Fracture Mechanics, Butterworth, London, 1973

[11]A.K. Vasudevan, R.D. Doherty: Acta Metall. Vol. 35 (1987), p. 1193-1219 